\title{
Prognostic Value of Circadian Brain Temperature Rhythm in Basal Ganglia Hemorrhage After Surgery
}

Hsueh-Yi Lu · Abel Po-Hao Huang · Lu-Ting Kuo

Received: August 5, 2021 / Accepted: September 7, 2021 / Published online: September 24, 2021

(C) The Author(s) 2021

\begin{abstract}
Introduction: Intracerebral hemorrhage (ICH) is associated with high mortality and morbidity rates. However, both the rhythmic variation and prognostic value of brain temperature after ICH remain unknown. In this study, we investigated brain temperature rhythm and its prognostic value for post-operative mortality and long-term functional outcomes in patients with ICH.

Methods: Post-operative diurnal brain temperature patterns at the basal ganglion are described. Following surgery for ICH, 78 patients were enrolled, and intracranial pressure and brain temperature were monitored using a fiber optic
\end{abstract}

H.-Y. Lu

Department of Industrial Engineering and Management, National Yunlin University of Science and Technology, Yun-Lin 640, Taiwan

e-mail: hylu@yuntech.edu.tw

A. P.-H. Huang · L.-T. Kuo ( $₫)$

Division of Neurosurgery, Department of Surgery,

National Taiwan University Hospital, No.7. Chung

San South Road, Taipei 100, Taiwan

e-mail: kuoluting@gmail.com

\section{A. P.-H. Huang}

Institute of Polymer Science and Engineering,

National Taiwan University, Taipei 100, Taiwan

e-mail: how.how0622@gmail.com device. Brain temperature mesor, amplitude, and acrophase were estimated from the recorded temperature measurements, using cosinor analysis, and the association between these patterns and clinical parameters, mortality, and functional outcomes at the 12-month follow-up were examined.

Results: According to cosinor analysis, brain temperature in $55.1 \%$ of patients showed a circadian rhythm within $72 \mathrm{~h}$ post-surgery. The rhythm-adjusted mesor of brain temperature ( \pm standard deviation) was $37.6( \pm 0.7)^{\circ} \mathrm{C}$, with a diminished mean amplitude. A temperature acrophase shift was also observed. Multivariate logistic regression analysis revealed that initial age and circadian rhythm of brain temperature appeared to be predictive and prognostic of functional outcomes. Further, patients with higher brain temperature mesor were more likely to survive than those with a lower mesor. Conclusion: For patients with ICH, brain temperature rhythm analysis is an improved prognostic tool for mortality and functional outcome predictions.

Keywords: Brain temperature rhythm; Intracerebral hemorrhage; Postoperative management 


\section{Key Summary Points}

Intracerebral hemorrhage (ICH) is associated with high mortality and morbidity rates. The rhythmic variation and prognostic value of brain temperature after ICH remain unknown.

This study investigated brain temperature rhythm and its prognostic value for postoperative mortality and long-term functional outcomes in patients with ICH.

According to cosinor analysis, $55.1 \%$ of patients showed circadian rhythm of brain temperature within $72 \mathrm{~h}$ postsurgery with a diminished mean amplitude.

Multivariate logistic regression analysis revealed that initial age and circadian rhythm of brain temperature appeared to be predictive and a prognostic factor of functional outcomes

Brain temperature rhythm analysis in patients with ICH improves outcome predictions.

\section{INTRODUCTION}

Intracerebral hemorrhage (ICH) is the deadliest form of stroke and the leading cause of disability and mortality worldwide. ICH accounts for approximately $20-40 \%$ of all strokes, and only $12-39 \%$ of survivors achieve long-term functional independence [1-6]. Improvement in diagnosis, surgical intervention, and intensive care has increased the survival rate of patients with ICH; however, long-lasting disability leads to significant functional, emotional, and economic sequelae [4-8]. Thus, it is important to identify ICH-related prognostic factors and establish prognostic models that can assist clinicians in communicating with the patient's family and in developing the appropriate treatment plan. Although previous studies have identified clinical parameters that can predict conscious and functional recovery [9-11], some patients with ICH have unpredictable outcomes during the early stage of treatment.

The circadian rhythm is a biological adaptation to the light-dark cycle which regulates sleep-wake cycles, body temperature, melatonin levels, and other important physiological functions. Brain temperature, a part of the circadian rhythm, mostly reflects body temperature under physiological conditions and brain metabolism. A previous study demonstrated changes in blood pressure (BP) and heart rate (HR) rhythms after ICH, which could be a early predictors of post-operative prognosis in patients with $\mathrm{ICH}$ [12]. However, to the best of our knowledge, no study has explored changes in brain temperature rhythm in patients with $\mathrm{ICH}$. Therefore, the aim of this study was to characterize brain temperature rhythms and investigate their prognostic value in terms of post-operative mortality and long-term functional outcomes in patients with ICH.

\section{METHODS}

\section{Study Design}

This was a prospective, observational study in which the clinical characteristics, brain temperature, and post-operative outcomes of patients with ICH at the basal ganglia were obtained for analysis. All patients were followed up until they regained a modified Rankin Scale (mRS) score of 0 or up to 12 months after surgery. The primary endpoint was mortality and functional outcomes following ICH surgery. This study was conducted at the National Taiwan University Hospital, in accordance with applicable local regulations and the Declaration of Helsinki. This study was approved by the Institutional Review Board of the National Taiwan University Hospital (IRB number: 201211025RIB). Written informed consent was obtained from the caregivers of patients, as patients were in a comatose state. 


\section{Study Population}

All patients eligible for inclusion in the study had been admitted to the National Taiwan University Hospital between May 2011 and December 2017. Patients with $>30 \mathrm{~mL}$ unilateral ICH at the basal ganglia, aged $>18$ years, who underwent ICH surgery with intracranial pressure (ICP) monitoring and had brain temperature data for $\geq 72 \mathrm{~h}$ post-surgery were included. Patients with pre-existing brain diseases (e.g., brain tumor, stroke, or meningitis), substance abuse (e.g., illicit drugs or alcohol), combined traumatic injuries (i.e., subdural hemorrhage, epidural hemorrhage, brain contusions, rib fracture, hemothorax, liver or spleen laceration, or bone fracture, except the skull bone), infection within $72 \mathrm{~h}$ after admission, or survival time $<3$ days after traumatic brain injury (TBI) surgery were excluded. To consider the effects of intraventricular hemorrhage (IVH) and subsequent hydrocephalus on patient outcome, patients who underwent external ventricular drainage for ventricular blood extension were excluded, as were those who signed a do-not-resuscitate order.

\section{Medical Procedure and Assessments}

Upon hospital admission, a physician evaluated the patient's Glasgow Coma Scale (GCS) score, and a brain computed tomography (CT) scan was conducted immediately. Prehospital management was completed according to the standards of the Taiwan Society of Emergency Medicine.

All patients underwent a surgical approach, which included endoscopy-assisted hematoma evacuation and intraparenchymal placement of a fiberoptic ICP monitor (Camino Laboratories, San Diego, CA, USA; model 110-4BT) based on the GCS score, pupillary examination findings, CT findings, age, hematoma volume, and occurrence of neurological deterioration (e.g., decrease in the GCS score or abnormal papillary response to light). Brain temperature was recorded using the ICP catheter, which was placed at a depth of approximately $3 \mathrm{~cm}$ from the brain surface.
All patients were admitted to the intensive care unit (ICU) after surgery. Brain temperature was continuously recorded using an ICP monitoring device, with a bolt screwed into the skull, and hourly data were collected for circadian rhythm analysis. Standard monitoring procedures at the ICU included invasive measurement of arterial BP (zero-point at the fourth intercostal space in the midclavicular line), pulse oximeter oxygen saturation, end-tidal $\mathrm{CO}_{2}$ concentration, and blood sugar level. Neurological assessments (e.g., GCS, pupil size, and pupil reflex to light) were performed hourly. Tympanic body temperature was measured every $3 \mathrm{~h}$. Mean arterial BP and ICP were monitored continuously.

Post-operative management included mechanical ventilation, oxygenation, fluid resuscitation, and use of antiepileptic drugs (i.e., valproic acid and levetiracetam). Hypothermia treatment was not applied, although antibiotic prophylaxis was administered to each patient for at least 3 days after surgery. Enteral feeding was initiated on postoperative day 2 , using a nasogastric or orogastric tube for patients without upper gastrointestinal hemorrhage. A 2-h ICP $>20 \mathrm{mmHg}$ during the first 3 days after surgery was considered to be the threshold to initiate a head CT scan and treatment; otherwise, a head CT scan was performed on post-operative day 3. If a patient complied with the weaning parameters for extubation from mechanical ventilation, he/ she was extubated. The ICP catheter was used until around post-operative day 7 if there was no increased ICP.

After transfer to the general ward, patients participated in rehabilitation programs and were followed up for at least 12 months in an outpatient setting. Post-operative follow-up included mRS assessment and evaluation of survival status. The mRS is a 7-point scale that measures the degree of disability in patients with stroke, with a score of 6 indicating death and 0 indicating good recovery without symptoms. It has been widely regarded in the literature that $\mathrm{mRS} \leq 2$ reflects independence while mRS $>2$ implies dependence [13-16]. In this study, unfavorable outcome was defined as an mRS score of 3-6 at 12 months post-surgery and 
favorable outcome as an mRS score of $\leq 2$ at 12 months. In this study, 58 patients $(74.36 \%)$ were found to have unfavorable outcomes. To examine the adequacy of the sample size for the detection of significant differences, the minimum sample size was 72 , which was obtained using the following simple formula [17]: $\mathbf{n}=$ $\frac{Z^{2} \boldsymbol{P}(1-\boldsymbol{P})}{\boldsymbol{d}^{2}}$ where we assumed a level of confidence $(z)$ of 1.96 , a precision level $(d)$ of $10 \%$, and an arbitrary figure of $0.75 \%$ as the proportion $(p)$ of unfavorable outcome.

\section{Brain Temperature Analysis}

Temperature measurements were divided into 24-h segments over a 72-h period, beginning from $2 \mathrm{~h}$ after surgery, to ensure sufficient temperature records for an unbiased estimation of cosinor parameters were obtained and to minimize potential confounders due to postoperative hypothermia.

Cosinor analysis involves fitting the brain temperature data to a 24-h cosine curve with estimates of circadian rhythm parameters, including the mesor (i.e., the circadian rhythmadjusted mean of temperature oscillations), the amplitude of temperature oscillations (defined as half of the difference between the lowest and highest temperature), and acrophase (i.e., the time when the temperature rhythm reached its maximum daily value) [18].

\section{Statistical Analyses}

The chi-squared test (or Fisher's exact test) and $t$ test were used to compare outcomes between patient subgroups for categorical and continuous data, respectively. Significant variables found in the univariate analysis were analyzed using multivariate logistic regression models constructed with stepwise selection to identify independent predictors of mortality and functional outcomes. Missing data were not included in the analysis. A $p$ value $<0.05$ was considered to indicate statistical significance. Data were analyzed using SPSS version 14.0 for Windows (SPSS IBM Corp., Armonk, NY, USA).
Table 1 Clinical parameters of patients

\begin{tabular}{|c|c|}
\hline Parameters & Results $(n=78)$ \\
\hline Male, $n(\%)$ & $50(64.1)$ \\
\hline \multicolumn{2}{|l|}{ Age, years } \\
\hline Mean $(S D)$ & $60.9(15.0)$ \\
\hline Median & 61.5 \\
\hline Range & $20-89$ \\
\hline $\mathrm{DM}, n(\%)$ & $16(20.5)$ \\
\hline HTN, $n(\%)$ & $55(70.5)$ \\
\hline \multicolumn{2}{|l|}{ Initial GCS score, $n(\%)$} \\
\hline $3-8$ & $46(59.0)$ \\
\hline $9-15$ & $32(41.0)$ \\
\hline \multicolumn{2}{|c|}{ 12-Month post-operative outcomes, $n$ (\%) } \\
\hline \multicolumn{2}{|l|}{$\mathrm{mRS}$} \\
\hline 1 & $19(24.4)$ \\
\hline 2 & $1(1.3)$ \\
\hline 3 & $24(30.8)$ \\
\hline 4 & $7(9.0)$ \\
\hline 5 & $18(23.1)$ \\
\hline 6 & $9(11.5)$ \\
\hline Favorable $(\mathrm{mRS}<3)$ & $20(25.6)$ \\
\hline Alive & $69(88.5)$ \\
\hline
\end{tabular}

$D M$ Diabetes mellitus, GCS Glasgow Coma Scale, HTN hypertension, $m R S$ modified Rankin Scale, $S D$ standard deviation

\section{RESULTS}

\section{Demographic Data}

Demographic and clinical characteristics of the study population are presented in Table 1.

We enrolled 78 patients who met the inclusion criteria. The majority were men (64.1\%), and the mean age \pm standard deviation (SD) was $60.9 \pm 15.0$ (range 20-89) years. All patients were diagnosed with $\mathrm{ICH}$ at the basal ganglia. Of these 78 patients, 55 (70.5\%) had a 


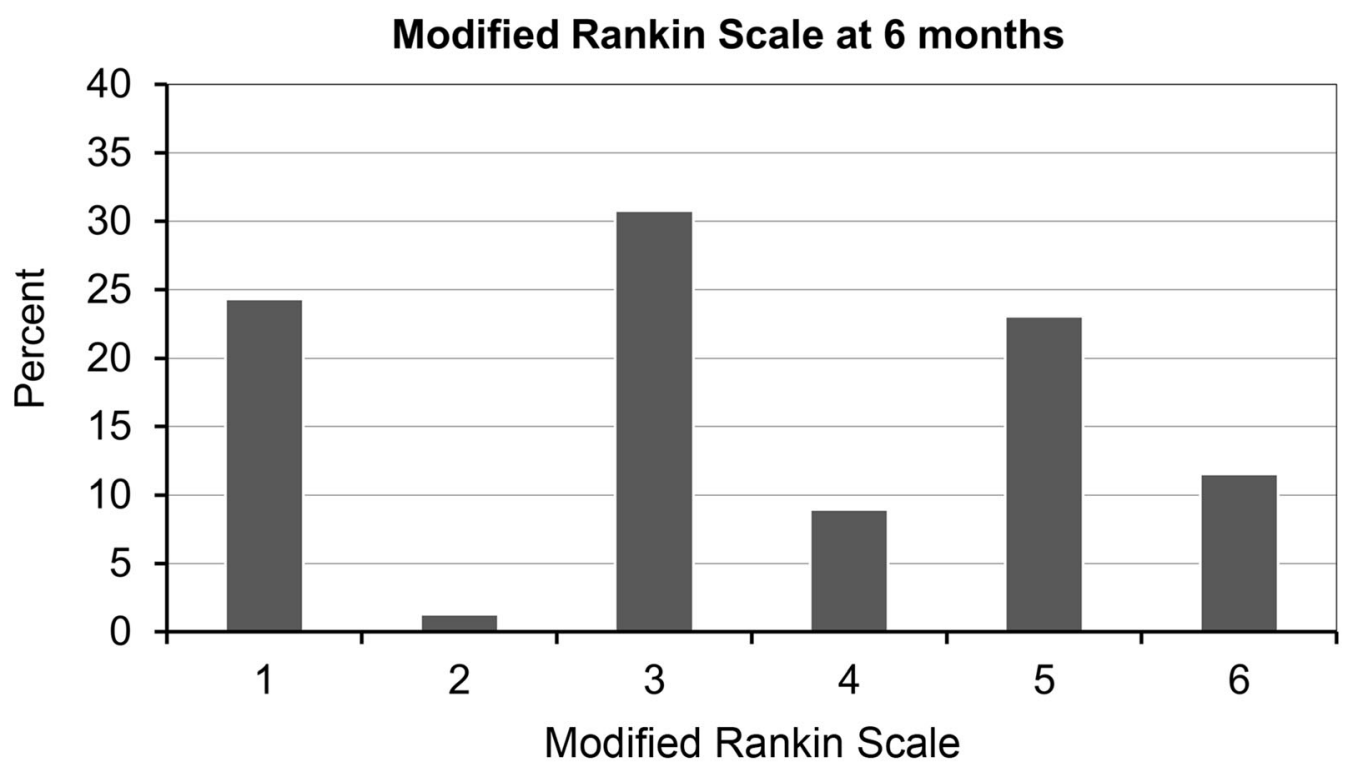

Fig. 1 Functional outcome at 12 months according to the modified Rankin Scale

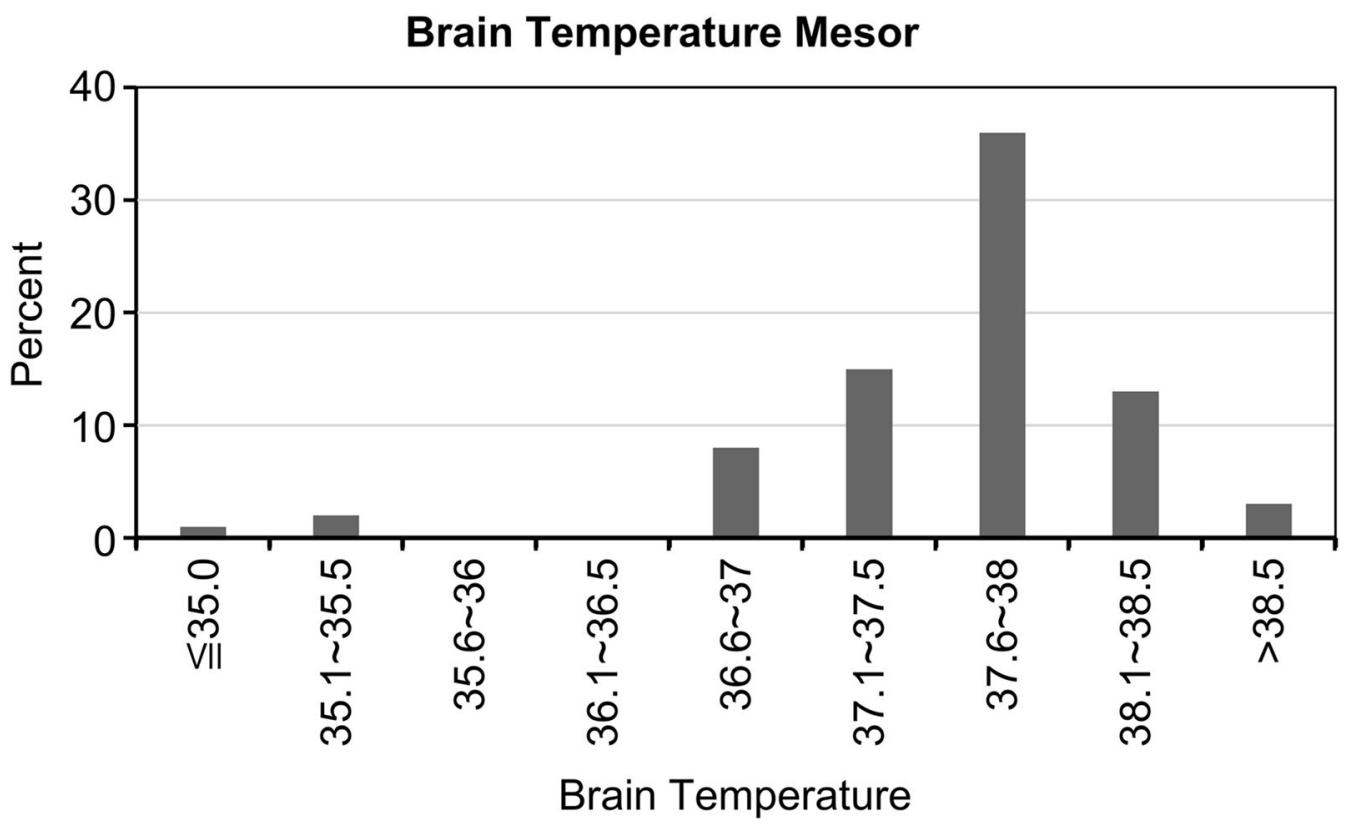

Fig. 2 Mesor of brain temperature. Temperature (in ${ }^{\circ} \mathrm{C}$ ) presented along the $x$-axis

history of hypertension and 16 (20.5\%) had diabetes mellitus. Upon arrival at the hospital, 46 patients $(59.0 \%)$ had a GCS score of 3-8 and $32(41.0 \%)$ had a GCS score of 9-12. The surgical approach to these ICH cases included craniotomy for hematoma evacuation and insertion of a fiber optic ICP monitoring device for brain temperature measurement.

\section{Postoperative Outcome}

At 12 months after surgery, 20 patients $(25.6 \%)$ showed favorable outcomes $(\mathrm{mRS}<3)$ and nine (11.5\%) had died (Table 1; Fig. 1). 
Table 2 Brain temperature analysis

\begin{tabular}{|c|c|}
\hline Characteristics & Results $(n=78)$ \\
\hline \multicolumn{2}{|c|}{ Brain temperature mesor $\left({ }^{\circ} \mathrm{C}\right)$} \\
\hline Mean (SD) & $37.6(0.7)$ \\
\hline$\leq 35.0, n(\%)$ & $1(1.3)$ \\
\hline $35.1-35.5$ & $2(2.6)$ \\
\hline $35.6-36.0$ & $0(0)$ \\
\hline $36.1-36.5$ & $0(0)$ \\
\hline $36.5-37.0$ & $8(10.3)$ \\
\hline $37.1-37.5$ & $15(19.2)$ \\
\hline $37.6-38.0$ & $36(46.2)$ \\
\hline $38.1-38.5$ & $13(16.7)$ \\
\hline$>38.5$ & $3(3.9)$ \\
\hline \multicolumn{2}{|c|}{ Circadian rhythm of brain temperature, $n(\%)$} \\
\hline Presence & $43(55.1)$ \\
\hline Absence & $35(44.9)$ \\
\hline \multicolumn{2}{|l|}{ Amplitude $\left({ }^{\circ} \mathrm{C}\right), n(\%)$} \\
\hline \multicolumn{2}{|l|}{ Mean (SD) } \\
\hline$\leq 0.4$ & $59(75.6)$ \\
\hline $0.41-0.6$ & $14(17.9)$ \\
\hline$>0.6$ & $5(6.4)$ \\
\hline \multicolumn{2}{|c|}{ Acrophase quadrant, $n$ (\%) } \\
\hline 00:01-06:00 hours & $7(9.0)$ \\
\hline 06:01-12:00 hours & $7(9.0)$ \\
\hline 12:01-18:00 hours & $31(39.7)$ \\
\hline 18:01-24:00 hours & $33(42.3)$ \\
\hline
\end{tabular}

\section{Characteristics of Brain Temperature Analysis}

The mesor $( \pm \mathrm{SD})$ was $37.6 \pm 0.7^{\circ} \mathrm{C}$, with $19.2 \%$ of patients showing $37.1-37.5^{\circ} \mathrm{C}, 46.2 \%$ showing $37.6-38.0^{\circ} \mathrm{C}$, and $16.7 \%$ showing 38.1-38.5 ${ }^{\circ} \mathrm{C}$ (Fig. 2; Table 2); the amplitude for the majority of patients $(75.6 \%)$ was $<0.4{ }^{\circ} \mathrm{C}$ (Fig. 3; Table 2). According to cosinor analysis, 43 patients $(55.1 \%)$ showed a circadian rhythm (Fig. 4; Table 2), defined as $R^{2} \geq 0.10$. The acrophase of 31 patients (39.7\%) fell between 12:00 and 18:00 hours, and the acrophase of 33 patients $(42.3 \%)$ peaked between 18:00 and 24:00 hours (Fig. 5; Table 2).

\section{Analysis of Post-operative Outcome Predictors}

Univariate analysis of post-operative outcomes revealed that sex, diabetes, initial GCS score, mesor within the middle $50 \%$ of its distribution, and brain temperature rhythm may be prognostic factors of post-operative functional outcomes (Table 3).

Compared with patients with unfavorable outcome (mRS 3-6) at 12 months, patients with favorable outcomes (mRS $<3$ ) at 12 months were mostly men, had higher GCS scores before surgery, and few had diabetes. Additionally, the cohort with favorable outcomes also showed a higher proportion of patients with mesor within the middle $50 \%$ of the distribution in the first $72 \mathrm{~h}$ after surgery and a higher proportion of patients with intact brain temperature rhythm, compared with those with an unfavorable outcome. Furthermore, initial white blood cell $>10,000 / \mu \mathrm{L}$ and the brain temperature mesor after surgery appeared to be prognostic factors of survival status at 1 year after surgery. Compared with the patients who died, a lower proportion of patients who were alive at 12 months had leukocytosis before surgery and a lower brain temperature mesor after surgery.

Potential predictors identified in the univariate analysis were included in the multivariate analysis (Table 4). Functional outcomes at 12 months after surgery were significantly associated with age and brain temperature rhythm. Specifically, patients with an intact brain temperature rhythm were 8.82 -fold more likely to have a favorable functional outcome at 12 months after surgery (odds ratio [OR] 8.82, 95\% confidence interval [CI) 2.00-39.02). In comparison, older patients were less likely to have a favorable outcome (OR 0.95, 95\% CI 0.91-0.99). Survival status at 12 months after surgery was significantly associated with the temperature mesor. The results revealed that 


\section{Amplitudes}

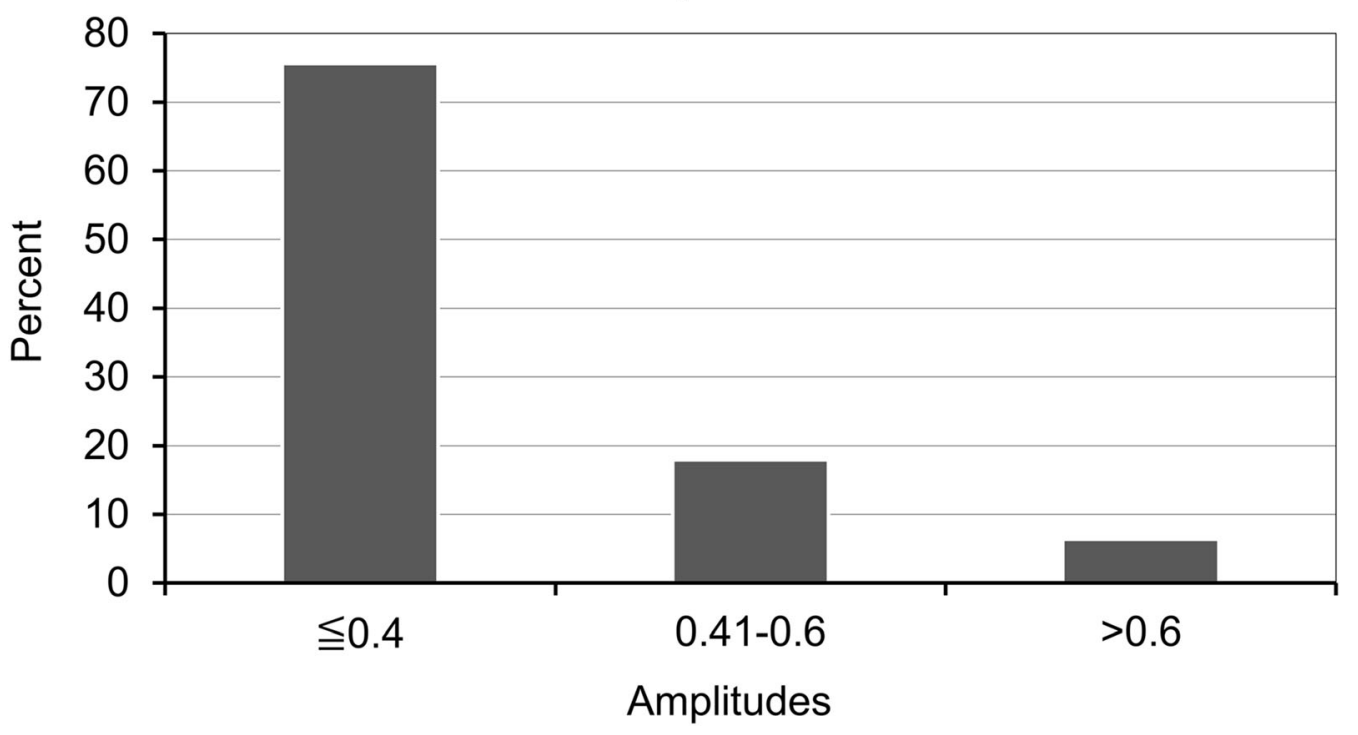

Fig. 3 Amplitude of brain temperature $\left({ }^{\circ} \mathrm{C}\right)$ in study population

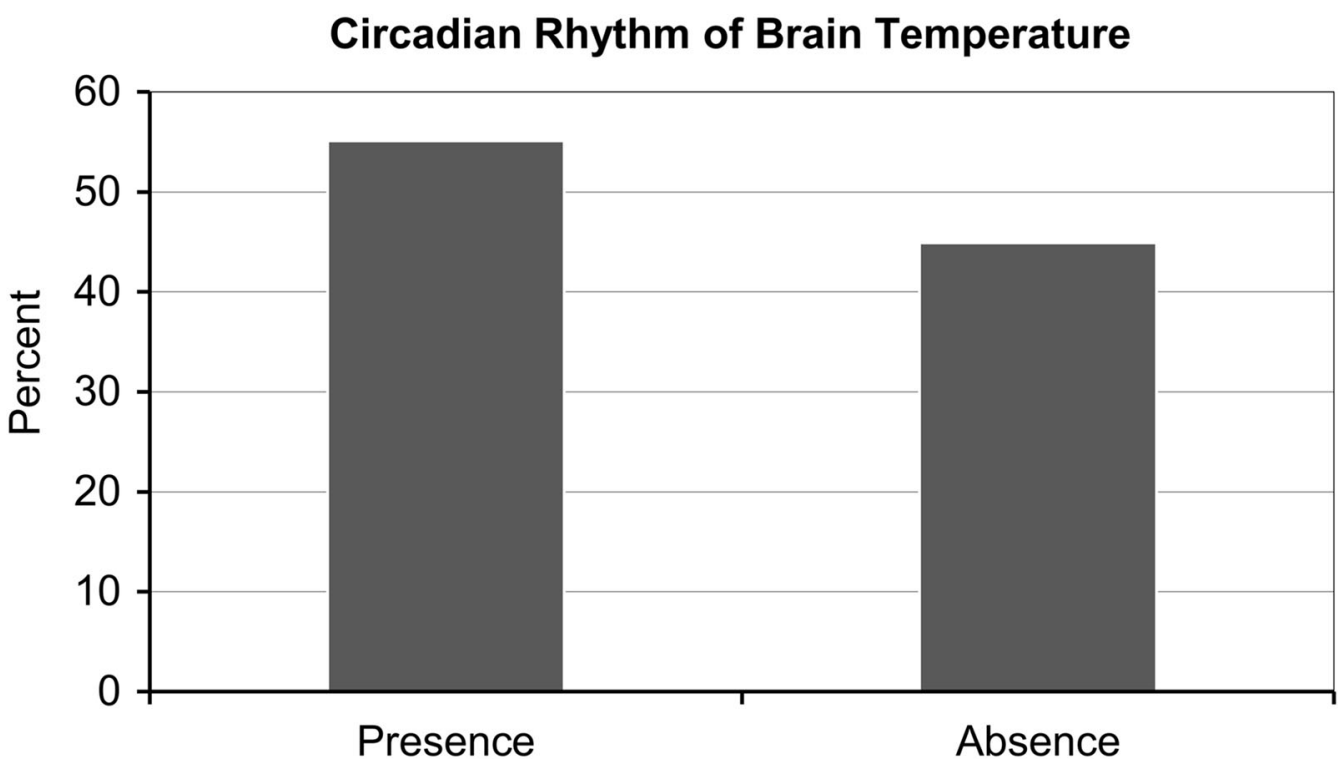

Fig. 4 Presence/absence of circadian rhythm of brain temperature

patients with lower brain temperature mesor were less likely to survive after surgery (OR 0.34, 95\% CI 0.14-0.83).

\section{DISCUSSION}

To the best of our knowledge, this study provides the first comprehensive characterization and analysis of brain temperature rhythm in patients who underwent surgery for ICH at the basal ganglia. We also examined the association of brain temperature rhythm with mortality 
Table 3 Univariate analysis for post-operative outcomes

\begin{tabular}{|c|c|c|c|c|c|c|}
\hline $\begin{array}{l}\text { Outcome } \\
\text { predictors }\end{array}$ & $\begin{array}{l}\text { Unfavorable outcome }{ }^{\mathrm{a}} \\
(n=58)\end{array}$ & $\begin{array}{l}\text { Favorable outcome }{ }^{\mathbf{a}} \\
(n=20)\end{array}$ & $p^{\mathbf{b}}$ & $\begin{array}{l}\text { Dead }^{\mathrm{c}} \\
(n=9)\end{array}$ & $\begin{array}{l}\text { Alive }{ }^{\mathrm{c}} \\
(n=69)\end{array}$ & $p^{\mathbf{b}}$ \\
\hline Male & $33(56.9)$ & $17(85.0)$ & $<0.05$ & $5(55.6)$ & $45(65.2)$ & 0.57 \\
\hline $\begin{array}{l}\text { Age, mean, years } \\
\text { (SD) }\end{array}$ & $62.76(14.94)$ & $55.65(14.14)$ & 0.07 & $\begin{array}{l}64.67 \\
(17.44)\end{array}$ & $\begin{array}{l}60.45 \\
\quad(14.70)\end{array}$ & 0.43 \\
\hline $\mathrm{DM}$ & $15(25.9)$ & $1(5.0)$ & $<0.05$ & $2(22.2)$ & $14(20.3)$ & 0.89 \\
\hline HTN & $40(69.0)$ & $15(75.0)$ & 0.61 & $5(55.6)$ & $50(72.5)$ & 0.30 \\
\hline $\mathrm{GCS} \leq 8$ & $39(67.2)$ & $7(35.0)$ & $<0.05$ & $8(88.9)$ & $38(55.1)$ & 0.05 \\
\hline $\begin{array}{l}\text { WBC }>10,000 / \\
\mu \mathrm{L}\end{array}$ & $28(48.3)$ & $7(35.0)$ & 0.30 & $7(77.8)$ & $28(40.6)$ & $<0.05$ \\
\hline $\begin{array}{l}\text { Glucose }>120 \mathrm{mg} / \\
\mathrm{dL}\end{array}$ & $35(60.3)$ & $10(50.0)$ & 0.42 & $6(66.7)$ & $39(56.5)$ & 0.56 \\
\hline $\begin{array}{l}\text { Mesor, mean, }{ }^{\circ} \mathrm{C} \\
\text { (SD) }\end{array}$ & $37.55(0.79)$ & $37.71(0.35)$ & 0.39 & $\begin{array}{l}36.87 \\
(1.60)\end{array}$ & $37.68(0.43)$ & $<0.01$ \\
\hline Mesor mid- $50 \%^{\mathrm{d}}$ & $25(43.1)$ & $14(70.0)$ & $<0.05$ & $2(22.2)$ & $37(53.6)$ & 0.08 \\
\hline $\begin{array}{l}\text { Intact rhythm of } \\
\mathrm{BT}^{\mathrm{e}}\end{array}$ & $26(44.8)$ & $17(85.0)$ & $<0.01$ & $5(55.6)$ & $38(55.1)$ & 0.98 \\
\hline
\end{tabular}

Values in table are presented as $n$ (\%), unless indicated otherwise

$B T$ Brain temperature, $W B C$ white blood cell

b $p$ values were accessed by $t$ the test for continuous variables and chi-square test for dichotomous variables

a Favorable outcome was defined as mRS score 0-2 at 12 months after surgery; unfavorable outcome was defined as mRS score 3-6 at 12 months after surgery

c Survival status was followed up at 12 months after surgery

d Within the middle $50 \%$ of the distribution in mesor

e Intact rhythm of BT was defined as fitting the $p$ value of the cosinor analysis $(p<0.05)$ for brain temperature

and 12-month functional outcome. All cases were treated with craniotomy alone within $12 \mathrm{~h}$ of an ictus, but none of the cases needed a subsequent craniectomy. Some studies mention that minimally invasive endoscopic evacuation is useful in early cases in contrast to delayed $(>48 \mathrm{~h}$ ) cases, which may need craniectomy with or without ICH evacuation [19-23]. Multivariate analysis of our findings demonstrated that age and an intact/absent brain temperature rhythm were significantly correlated with functional outcomes at 12 months after surgery, while only the brain temperature mesor after surgery was associated with patient survival at 12 months.
Various predictive models for death and functional outcome in patients with ICH have been reported. Important outcome predictors in ICH include age, GCS score, ICH volume, presence of IVH, deep or infratentorial ICH location, and preceding oral anticoagulant use $[20,24,25]$. There are also three major clinical prediction scores: the ICH score [9], GCS score [10], and FUNC score, with the latter rating prognosis for good neurologic outcome on an 11-point scale [11]. The ICH and GCS scores correlated well with mortality in our analysis. The use of these scores is recommended, as they are useful for early decision-making for patients and their family members. However, for patients with ICH scheduled for surgery, there 
Table 4 Multivariate analysis for post-operative outcomes

\begin{tabular}{lcclll}
\hline Outcome predictors & \multicolumn{2}{l}{ Functional outcome $^{\mathbf{a}}$} & & \multicolumn{2}{l}{ Survival outcome $^{\mathbf{b}}$} \\
\cline { 2 - 3 } & Coefficient & OR (95\% CI) & & Coefficient & OR (95\% CI) \\
\hline Sex & 1.10 & $3.01(0.68-13.36)$ & & \\
Age & $-0.05^{*}$ & $0.95(0.91-0.99)$ & & \\
DM & -2.01 & $0.13(0.01-1.84)$ & & \\
GCS & 0.19 & $1.20(0.97-1.50)$ & & -1.35 & $0.23(0.03-2.40)$ \\
WBC $>10,000 / \mu \mathrm{L}$ & & & 1.68 & $5.25(0.81-35.51)$ \\
Mesor & & & $-1.07^{*}$ & $0.34(0.14-0.83)$ \\
Intact rhythm of BT & $2.18^{* *}$ & $8.82(2.00-39.02)$ & & \\
\hline
\end{tabular}

$O R$ Odds ratio, $C I$ confidence interval

${ }^{*} p<0.05,{ }^{* *} p<0.01$

${ }^{a}$ Functional outcome, defined as unfavorable/favorable ratio, with favorable outcome defined as mRS score 0-2 at 12 months after surgery, and unfavorable outcome as mRS score 3-6 at 12 months after surgery

b Survival outcome, defined as the alive/dead ratio, was followed up at 12 months after surgery

${ }^{c}$ Intact rhythm of BT was defined as fitting the $p$ value of the cosinor analysis $(p<0.05)$ for brain temperature

appears to be limited literature on outcome prediction.

Regarding the role of age in predicting functional outcomes, our findings are consistent with those of previously established prognostic models $[26,27]$. The initial GCS score in patients with an unfavorable outcome was significantly lower than that in patients with a favorable outcome. However, no significant difference was noted after multivariate analysis (OR 1.2, 95\% CI 0.97-1.50).

Our study showed that the percentage of patients with leukocytosis before surgery, defined as $\mathrm{WBC}>10,000 / \mu \mathrm{L}$, significantly differed between the mortality and survival groups at 12 months. Of the nine deceased patients, $77.8 \%$ had leukocytosis. In contrast, only 28 $(40.6 \%)$ of the 69 patients who survived for $>1$ year after surgery had leukocytosis. However, this parameter showed no significant difference in the multivariate analysis. Inflammation is one of the key pathological pathways involved in secondary ICH injury, and cytokines can regulate leukocyte migration to the hematoma and facilitate secondary brain injury [28-30]. Leukocytosis or the increased ratio of absolute neutrophil to absolute lymphocyte count is associated with poor functional outcomes and higher mortality after ICH [31, 32]. The effectiveness of anti-inflammatory therapy for ICH in humans remains questionable because of potential complications, despite the neuroprotective effects of the inhibition of neuroinflammation and therapeutic hypothermia shown in animal models [29, 33, 34, 35].

Brain temperature is mainly dependent on cerebral blood flow, blood temperature, and cerebral metabolism. Fiber optic catheters for continuous ICP and brain temperature measurement were placed into the brain parenchyma through bolts, with the catheter tip placed approximately $3 \mathrm{~cm}$ from the dura. Brain temperature is normally approximately $0.3^{\circ} \mathrm{C}$ higher than the body core temperature $[36,37]$. In addition to the absolute temperature, circadian rhythms are another feature of brain and body temperatures. The suprachiasmatic nuclei (SCN) in the anterior part of the hypothalamus serve as a central pacemaker for multiple biological rhythms. Cosinor analysis was strictly performed a 24-h intervals in this study, which is the most commonly used model for describing rhythmic temperature patterns. Studies involving brain injury patients support a period 


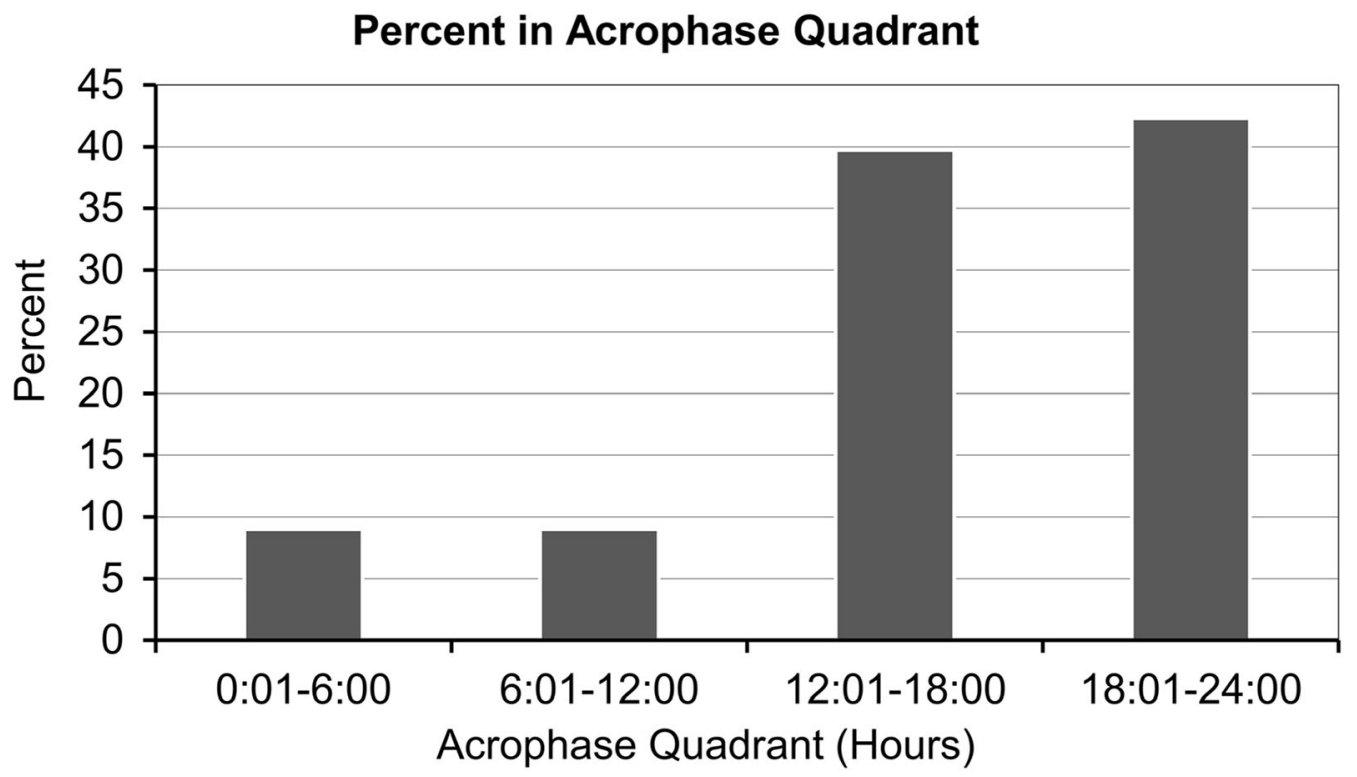

Fig. 5 Acrophase of brain temperature

of approximately $24 \mathrm{~h}$ for body temperature and BP assessment [38-40]. Our study identified a mesor $>37.5^{\circ} \mathrm{C}$ in $66.6 \%$ of patients. The elevation of brain temperature after ICH may imply a reset of the thermoregulatory center in the hypothalamus, metabolic changes in the injured brain, hyperemia, or a local inflammatory response [41-43]. Our results demonstrate that patients with a higher brain temperature mesor during the first 3 days after ICH surgery had a better chance of survival, according to multivariate analysis. Previous studies suggested that patients with the highest and lowest average brain temperatures after TBI were more likely to have poor outcomes [44, 45], and some studies have shown associations between elevated body temperature at admission and poor outcomes in nonsurgical patients with stroke $[46,47]$. A retrospective study showed that surgical evacuation was a significant predictor of fever in patients with ICH and that the location of hemorrhage also influences body temperature, especially in the brainstem, thalamus, or ventricles [48]. In our study, the lower mesor of the 3-day brain temperature after surgery was an independent predictor of 12-month mortality, with only putaminal hemorrhage included. Since we analyzed brain temperature mesors instead of absolute body temperature values, elevated temperature as outcome predictor was not comparable to the temperature definition of fever in other studies. In nonsurgical patients, hematoma growth with surrounding brain edema, brain-blood barrier breakdown, inflammation, and glutamate excitotoxicity may be associated with poor outcomes in those with fever $[5,49]$. Further, the inversion of the brain/body temperature gradient was previously associated with poor outcomes in severe TBI $[45,50,51]$.

Cosinor analysis in this study identified changes in brain temperature rhythm after ICH. Brain temperature rhythm was absent in $44.9 \%$ of patients with $\mathrm{ICH}$, and the amplitude of brain temperature changes was blunted in $75.6 \%$ of patients, with $60.3 \%$ of the latter showing a shift in the acrophase. Rhythmic alterations in brain temperature were significantly correlated with functional outcome at 12 months after surgery. Jain et al. reported loss of nocturnal BP decline in $44(88 \%)$ of 50 patients with stroke, and 23 of these 44 patients showed reverse dipping with a nighttime BP increase compared with daytime levels [52]. In a study including 17 patients with stroke, the circadian variations of BP, neurohumoral, and coagulation factors were decreased; these decreases were mainly attributed to autonomic 
nervous disturbances after stroke [53]. Guan et al. analyzed rhythmic changes in systolic BP (SBP), diastolic BP (DBP), and HR during the first $24 \mathrm{~h}$ after surgery in 100 patients with $\mathrm{ICH}$, reporting the absence of SBP, DBP, and HR rhythms in 43,46 , and $52 \%$ of patients, respectively. Functional outcomes were better in patients with SBP, DBP, and HR rhythms compared to those patients with absence of SBP, DBP, and HR rhythms [12]. In another study including 86 patients with subarachnoid hemorrhage after cerebral aneurysm rupture, $89 \%$ of patients had preserved diurnal body temperature rhythm [54], and cosinor analysis revealed elevated mesors, diminished amplitude, and an acrophase shift [54]. Although not completely comparable to our study population, studies including mixed brain injury and ICU patients have also reported an acrophase shift $[38,55]$. These studies have demonstrated that biological rhythm may be disturbed in patients with stroke, even if there was no direct injury to the SCN. Moreover, there is a case report of a patient with subarachnoid and intraventricular hemorrhage around the hypothalamus due to a posterior fossa arteriovenous fistula who showed circadian rhythm disruption and reverse paradoxical insomnia upon polysomnography and actigraphy [56].

The disturbances of brain temperature rhythm, with diminished amplitude and acrophase shift after ICH, may be explained by contributing factors, such as direct or indirect injury to the hypothalamus, pharmacological treatment, nursing activities, and environmental factors in the ICU. Previous studies have demonstrated that TBI may cause microscopic hemorrhages of the retinohypothalamic tract, which transmits photic information from retinal ganglion cells to the hypothalamus and may lead to circadian rhythm disruption [57]. Increased ICP and stress after TBI may cause apoptosis in the hypothalamus and pituitary gland, leading to hypothalamic pituitary dysfunction $[58,59,60]$. In our study, we included only patients with putaminal hemorrhage, who may not have this kind of direct injury to the retinohypothalamic tract or SCN. Increased ICP before surgical evacuation or focal edema before/after surgery are considered to be the main possible mechanisms leading to SCN dysfunction or injury, compression of hypothalamic structures, and impairment of endogenous regulatory mechanisms. ICH may also lead to changes in cerebral blood flow, metabolic derangement, and a neurogenic inflammatory response, all of which may affect brain temperature stability $[61,62]$. The presence or absence of the circadian rhythm of brain temperature after ICH may indicate profound neuronal damage, and the extent of hypothalamic damage may correlate with outcomes. Our results correspond with the above findings and demonstrate that, in addition to age, the presence of a brain temperature rhythm may independently predict 12-month functional outcomes.

Another possible mechanism is the disruption of the diurnal sleep/wake pattern due to exogenous factors, including ICU hospitalization, loss of zeitgebers, and the use of sedativehypnotic drugs. Post-operative care in the ICU, where there is a lack of normal synchronizing influences, may lead to disturbance of brain temperature rhythms. Evidence has suggested that the use of sedating medications for mechanically ventilated patients in the ICU may lead to temporal disorganization of preserved circadian rhythms [63]. Considering that multiple factors may contribute to the disturbance of brain temperature rhythms and the acrophase shift, further research is required to characterize other potential factors.

This study had some limitations. First, the heterogeneity of patients' characteristics, including age, hematoma size, and comorbidities, may have affected the study outcomes. The effects of age on the pattern of circadian rhythms, such as a decrease in magnitude, lower mean values, and greater intra- and interindividual differences, should be considered. Interestingly, studies have confirmed that a relatively stable rhythm of core body temperature is observed in old age, persisting until the end of life [64]. Second, in this study we analyzed the clinical data of a small population patients with ICH in a single hospital; therefore, the study results are not generalizable. Additional studies with a larger population from multiple centers are required. Despite the above 
limitations, our findings suggest that brain temperature parameters have clinical implications in the management of $\mathrm{ICH}$, especially for decision-making involving communication between the patient's family, neurosurgeons, and neurocritical care experts. Early outcome prediction may facilitate communication to achieve optimal management and to avoid deleterious effects to the patient, family, and healthcare system.

\section{CONCLUSIONS}

In summary, to the best of our knowledge, this is the first study to investigate the circadian brain temperature rhythm in the acute stage of ICH and its correlation with mortality and functional outcomes. Our findings suggest that presence of circadian brain temperature rhythm in the first $72 \mathrm{~h}$ after surgery may be a predictor of mortality and long-term functional outcomes.

\section{ACKNOWLEDGEMENTS}

We thank the participants of the study.

Funding. This study was funded by the National Taiwan University Hospital, Yun-Lin Branch, grant number NTUHYL102.X007. LuTing Kuo provided the funding for the journal's Rapid Service Fee.

Editorial Assistance. We would like to thank Editage (www.editage.com) for English language editing. Lu-Ting Kuo provided the funding for this assistance.

Authorship. All named authors meet the International Committee of Medical Journal Editors (ICMJE) criteria for authorship for this article, take responsibility for the integrity of the work as a whole, and have given their approval for this version to be published.

Authors' Contributions. Methodology: L-TK and H-YL; investigation: AP-HH and LTK; formal analysis: L-TK and H-YL; data curation: AP-
$\mathrm{HH}, \mathrm{L}-\mathrm{TK}$, and H-YL; writing original draft: AP$\mathrm{HH}, \mathrm{L}-\mathrm{TK}$, and H-YL; writing, review and editing: AP-HH, L-TK, and H-YL.

Disclosures. Hsueh-Yi Lu, Abel Po-Hao Huang, Lu-Ting Kuo declare no conflict of interest. The funder had no role in the design of the study, in the collection, analyses, and interpretation of data, in the writing of the manuscript, or in the decision to publish the results.

Compliance with Ethics Guidelines. The study was conducted according to the guidelines of the Declaration of Helsinki of 1964 and its later amendments and approved by the Institutional Review Board of the National Taiwan University Hospital (IRB number: 201506084RIB). Written informed consent has been obtained from the patients' caregivers to publish this paper (the patients were comatose).

Data Availability. All data generated or analyzed during this study are included in this published article.

Open Access. This article is licensed under a Creative Commons Attribution-NonCommercial 4.0 International License, which permits any non-commercial use, sharing, adaptation, distribution and reproduction in any medium or format, as long as you give appropriate credit to the original author(s) and the source, provide a link to the Creative Commons licence, and indicate if changes were made. The images or other third party material in this article are included in the article's Creative Commons licence, unless indicated otherwise in a credit line to the material. If material is not included in the article's Creative Commons licence and your intended use is not permitted by statutory regulation or exceeds the permitted use, you will need to obtain permission directly from the copyright holder. To view a copy of this licence, visit http://creativecommons.org/licenses/by$\mathrm{nc} / 4.0 /$. 


\section{REFERENCES}

1. An SJ, Kim TJ, Yoon BW. Epidemiology, risk factors, and clinical features of intracerebral hemorrhage: an update. J Stroke. 2017;19:3-10. https://doi.org/ 10.5853/jos.2016.00864.

2. Caceres JA, Goldstein JN. Intracranial hemorrhage. Emerg Med Clin North Am. 2012;30:771-94. https://doi.org/10.1016/j.emc.2012.06.003.

3. de Oliveira Manoel AL. Surgery for spontaneous intracerebral hemorrhage. Crit Care. 2020;24:45. https://doi.org/10.1186/s13054-020-2749-2.

4. Feigin VL, Lawes CM, Bennett DA, Barker-Collo SL, Parag V. Worldwide stroke incidence and early case fatality reported in 56 population-based studies: A systematic review. Lancet Neurol. 2009;8:355-69. https://doi.org/10.1016/S1474-4422(09)70025-0.

5. Balami JS, Buchan AM. Complications of intracerebral hemorrhage. Lancet Neurol. 2012;11: 101-18. https://doi.org/10.1016/S14744422(11)70264-2.

6. Gross BA, Jankowitz BT, Friedlander RM. Cerebral intraparenchymal hemorrhage: a review. JAMA. 2019;321:1295-303. https://doi.org/10.1001/jama. 2019.2413 .

7. Kobata H, Ikeda N. Recent updates in neurosurgical interventions for spontaneous intracerebral hemorrhage: minimally invasive surgery to improve surgical performance. Front Neurol. 2021;12: 703189. https://doi.org/10.3389/fneur.2021.

703189.

8. Planton M, Raposo N, Danet L, Albucher JF, Peran $\mathrm{P}$, Pariente J. Impact of spontaneous intracerebral hemorrhage on cognitive functioning: an update. Rev Neurol (Paris). 2017;173:481-9. https://doi.org/ 10.1016/j.neurol.2017.06.010.

9. Hemphill JC, Bonovich DC, Besmertis L, Manley GT, Johnston SC. The ICH score: a simple, reliable grading scale for intracerebral hemorrhage. Stroke. 2001;32:891-7. https://doi.org/10.1161/01.str.32.4. 891.

10. Parry-Jones AR, Abid KA, Di Napoli M, et al. Accuracy and clinical usefulness of intracerebral hemorrhage grading scores: a direct comparison in a UK population. Stroke. 2013;44:1840-5. https://doi. org/10.1161/STROKEAHA.113.001009.

11. Rost NS, Smith EE, Chang Y, et al. Prediction of functional outcome in patients with primary intracerebral hemorrhage: the FUNC score. Stroke. 2008;39:2304-9.

STROKEAHA.107.512202.
12. Guan J, Ding Y, Liu Y, Li Y, Liu Y, Wang Z. Circadian effects on outcome following surgery for intracerebral hemorrhage in humans? Brain Res. 2009;1258:78-85. https://doi.org/10.1016/j. brainres.2008.11.106.

13. Ji R, Wang W, Liu X, et al. Head-to-head comparison of prognostic models of spontaneous intracerebral hemorrhage: tools for personalized care and clinical trial in ICH. Neurol Res. 2021. https://doi. org/10.1080/01616412.2021.1967678.

14. Kupper C, Feil K, Wollenweber FA, et al. Endovascular stroke treatment in orally anticoagulated patients: an analysis from the German Stroke Registry-Endovascular Treatment. J Neurol. 2021;268: 1762-9. https://doi.org/10.1007/s00415-02010369-6.

15. Lee EJ, Bae J, Jeong HB, Lee EJ, Jeong HY, Yoon BW. Effectiveness of mechanical thrombectomy in cancer-related stroke and associated factors with unfavorable outcome. BMC Neurol. 2021;21:57. https:// doi.org/10.1186/s12883-021-02086-y.

16. Roaldsen MB, Jusufovic M, Berge E, Lindekleiv $H$. Endovascular thrombectomy and intra-arterial interventions for acute ischaemic stroke. Cochrane Database Syst Rev. 2021;6:CD007574. https://doi. org/10.1002/14651858.CD007574.pub3.

17. Pourhoseingholi MA, Vahedi M, Rahimzadeh M. Sample size calculation in medical studies. Gastroenterol Hepatol Bed Bench. 2013;6:14-7.

18. Halberg F. Chronobiology. Annu Rev Physiol. 1969;31:675-725. https://doi.org/10.1146/annurev. ph.31.030169.003331.

19. Ali M, Yaeger K, Ascanio L, Troiani Z, Mocco J, Kellner CP. Early minimally invasive endoscopic intracerebral hemorrhage evacuation. World Neurosurg. 2021;148:115. https://doi.org/10.1016/j. wneu.2021.01.017.

20. Leira R, Davalos A, Silva Y, et al. Early neurologic deterioration in intracerebral hemorrhage: predictors and associated factors. Neurology. 2004;63: 461-7. https://doi.org/10.1212/01.wnl. 0000133204.81153.ac.

21. Fung C, Murek M, Z'Graggen WJ, et al. Decompressive hemicraniectomy in patients with supratentorial intracerebral hemorrhage. Stroke. 2012;43:3207-11. https://doi.org/10.1161/ STROKEAHA.112.666537.

22. Horowitz ME, Ali M, Chartrain AG, et al. Definition and time course of pericavity edema after minimally invasive endoscopic intracerebral hemorrhage evacuation. J Neurointerv Surg. 2021. https:// doi.org/10.1136/neurintsurg-2020-017077. 
23. Kuo LT, Chen CM, Li CH, et al. Early endoscopeassisted hematoma evacuation in patients with supratentorial intracerebral hemorrhage: case selection, surgical technique, and long-term results. Neurosurg Focus. 2011;30:E9. https://doi.org/10. 3171/2011.2.FOCUS10313.

24. Luzzi S, Elia A, Del Maestro M, et al. Indication, timing, and surgical treatment of spontaneous intracerebral hemorrhage: systematic review and proposal of a management algorithm. World Neurosurg. 2019. https://doi.org/10.1016/j.wneu.2019. 01.016.

25. Liu YB, Kuo LT, Chen CH, et al. Surgery for coagulopathy-related intracerebral hemorrhage: craniotomy vs minimally invasive neurosurgery. Life. 2021;11(6): 564. https://doi.org/10.3390/life11060564.

26. Rodriguez-Luna D, Rubiera M, Ribo M, et al. Ultraearly hematoma growth predicts poor outcome after acute intracerebral hemorrhage. Neurology. 2011;77:1599-604. https://doi.org/10.1212/WNL. ob013e3182343387.

27. Lannoo E, Van Rietvelde F, Colardyn F, et al. Early predictors of mortality and morbidity after severe closed head injury. J Neurotrauma. 2000;17: 403-14. https://doi.org/10.1089/neu.2000.17.403.

28. Prisco L, Iscra F, Ganau M, Berlot G. Early predictive factors on mortality in head injured patients: a retrospective analysis of 112 traumatic brain injured patients. J Neurosurg Sci. 2012;56:131-6.

29. Aronowski J, Zhao X. Molecular pathophysiology of cerebral hemorrhage: secondary brain injury. Stroke. 2011;42:1781-6. https://doi.org/10.1161/ STROKEAHA.110.596718.

30. Wang J. Preclinical and clinical research on inflammation after intracerebral hemorrhage. Prog Neurobiol. 2010;92:463-77. https://doi.org/10. 1016/j.pneurobio.2010.08.001.

31. Lattanzi S, Cagnetti C, Provinciali L, Silvestrini M. Neutrophil-to-lymphocyte ratio and neurological deterioration following acute cerebral hemorrhage. Oncotarget. 2017;8:57489-94. https://doi.org/10. 18632/oncotarget.15423.

32. Agnihotri S, Czap A, Staff I, Fortunato G, McCullough LD. Peripheral leukocyte counts and outcomes after intracerebral hemorrhage. J Neuroinflammation. 2011;8:160. https://doi.org/ 10.1186/1742-2094-8-160.

33. Bestue-Cardiel M, Martin-Martinez J, IturriagaHeras C, Ara-Callizo JR, Oliveros-Juste A. Leucocitos y hemorragia intracerebral primaria [Leukocytes and primary intracerebral hemorrhage]. Rev
Neurol. 1999;29:968-71. https://doi.org/10.33588/ rn.2910.99087.

34. Song F, Guo C, Geng Y, Wu X, Fan W. Therapeutic time window and regulation of autophagy by mild hypothermia after intracerebral hemorrhage in rats. Brain Res. 2018;1690:12-22. https://doi.org/10. 1016/j.brainres.2018.04.005.

35. Deng S, Jin P, Sherchan P, et al. Recombinant CCL17-dependent CCR4 activation alleviates neuroinflammation and neuronal apoptosis through the PI3K/AKT/Foxo1 signaling pathway after ICH in mice. J Neuroinflammation. 2021;18:62. https:// doi.org/10.1186/s12974-021-02112-3.

36. Rossi S, Zanier ER, Mauri I, Columbo A, Stocchetti N. Brain temperature, body core temperature, and intracranial pressure in acute cerebral damage. J Neurol Neurosurg Psychiatry. 2001;71:448-54. https://doi.org/10.1136/jnnp.71.4.448.

37. Childs C, Lunn KW. Clinical review: Brain-body temperature differences in adults with severe traumatic brain injury. Crit Care. 2013;17:222. https:// doi.org/10.1186/cc11892.

38. Fujishima I, Motohashi Y. Desynchronization of body temperature and blood pressure: circadian rhythms in patients after subarachnoid hemorrhage. Jpn J Psychiatry Neurol. 1991;45:159-60.

39. Alster J, Pratt H, Feinsod M. Density spectral array, evoked potentials, and temperature rhythms in the evaluation and prognosis of the comatose patient. Brain Inj. 1993;7:191-208. https://doi.org/10.3109/ 02699059309029672 .

40. Kropyvnytskyy I, Saunders F, Pols M, Zarowski C. Circadian rhythm of temperature in head injury. Brain Inj. 2001;15:511-8. https://doi.org/10.1080/ 02699050010007515.

41. Takekawa H, Miyamoto M, Miyamoto T, Yokota N, Hirata K. Alteration of circadian periodicity in core body temperatures of patients with acute stroke. Psychiatry Clin Neurosci. 2002;56:221-2. https:// doi.org/10.1046/j.1440-1819.2002.00994.x.

42. Goodman JC, Valadka AB, Gopinath SP, Uzura M, Robertson CS. Extracellular lactate and glucose alterations in the brain after head injury measured by microdialysis. Crit Care Med. 1999;27:1965-73. https://doi.org/10.1097/00003246-199909000-00041.

43. Marion DW, Darby J, Yonas H. Acute regional cerebral blood flow changes caused by severe head injuries. J Neurosurg. 1991;74:407-14. https://doi. org/10.3171/jns.1991.74.3.0407.

44. Goss JR, Styren SD, Miller PD, et al. Hypothermia attenuates the normal increase in interleukin 1 beta 
RNA and nerve growth factor following traumatic brain injury in the rat. J Neurotrauma. 1995;12: 159-67. https://doi.org/10.1089/neu.1995.12.159.

45. Childs C, Vail A, Leach P, Rainey T, Protheroe R, King A. Brain temperature and outcome after severe traumatic brain injury. Neurocrit Care. 2006;5: 10-4. https://doi.org/10.1385/NCC:5:1:10.

46. Soukup J, Zauner A, Doppenberg EM, et al. The importance of brain temperature in patients after severe head injury: relationship to intracranial pressure, cerebral perfusion pressure, cerebral blood flow, and outcome. J Neurotrauma. 2002;19: 559-71. 089771502753754046 .

47. Malavera A, You S, Zheng D, Delcourt C, Anderson $\mathrm{CS}$, Investigators I. Prognostic significance of early pyrexia in acute intracerebral haemorrhage: the INTERACT2 study. J Neurol Sci. 2021;423:117364. https://doi.org/10.1016/j.jns.2021.117364.

48. Wang Y, Lim LL, Levi C, Heller RF, Fisher J. Influence of admission body temperature on stroke mortality. Stroke. 2000;31:404-9. https://doi.org/ 10.1161/01.str.31.2.404.

49. Gillow SJ, Ouyang B, Lee VH, John S. Factors associated with fever in intracerebral hemorrhage. J Stroke Cerebrovasc Dis. 2017;26:1204-8. https:// doi.org/10.1016/j.jstrokecerebrovasdis.2017.01. 007.

50. Iglesias-Rey R, Rodriguez-Yanez M, Arias S, et al. Inflammation, edema and poor outcome are associated with hyperthermia in hypertensive intracerebral hemorrhages. Eur J Neurol. 2018;25:1161-8. https://doi.org/10.1111/ene.13677.

51. Fountas KN, Kapsalaki EZ, Feltes $\mathrm{CH}$, et al. Disassociation between intracranial and systemic temperatures as an early sign of brain death. J Neurosurg Anesthesiol. 2003;15:87-9. https://doi. org/10.1097/00008506-200304000-00004.

52. Jain S, Namboodri KK, Kumari S, Prabhakar S. Loss of circadian rhythm of blood pressure following acute stroke. BMC Neurol. 2004;4:1. https://doi. org/10.1186/1471-2377-4-1.

53. Eguchi K, Kario K, Shimada K, Mori T, Nii T, Ibaragi K. Circadian variation of blood pressure and neurohumoral factors during the acute phase of stroke. Clin Exp Hypertens. 2002;24:109-14. https://doi. org/10.1081/ceh-100108721.

54. Kirkness CJ, Burr RL, Thompson HJ, Mitchell PH. Temperature rhythm in aneurysmal subarachnoid hemorrhage. Neurocrit Care. 2008;8:380-90. https://doi.org/10.1007/s12028-007-9034-y.
55. Tweedie IE, Bell CF, Clegg A, et al. Retrospective study of temperature rhythms of intensive care patients. Crit Care Med. 1989;17:1159-65. https:// doi.org/10.1097/00003246-198911000-00012.

56. Attarian H. Circadian rhythm disruption and reverse paradoxical insomnia after intraventricular hemorrhage. Sleep Med. 2009;10:932-4. https:// doi.org/10.1016/j.sleep.2009.02.004.

57. Pizza F, Vetrugno R, Antelmi E, Pierangeli G, Montagna P, Cortelli P. Narcoleptic-like hypersomnia and inverted circadian rhythm of body core temperature after traumatic brain injury involving the hypothalamus. Sleep Med. 2011;12:1044-5. https://doi.org/10.1016/j.sleep.2011.06.013.

58. Ayalon L, Borodkin K, Dishon L, Kanety H, Dagan Y. Circadian rhythm sleep disorders following mild traumatic brain injury. Neurology. 2007;68: 1136-40. https://doi.org/10.1212/01.wnl. 0000258672.52836.30.

59. Tan H, Yang W, Wu C, et al. Assessment of the role of intracranial hypertension and stress on hippocampal cell apoptosis and hypothalamic-pituitary dysfunction after TBI. Sci Rep. 2017;7:3805. https://doi.org/10.1038/s41598-017-04008-w.

60. Karamouzis I, Pagano L, Prodam F, et al. Clinical and diagnostic approach to patients with hypopituitarism due to traumatic brain injury (TBI), subarachnoid hemorrhage (SAH), and ischemic stroke (IS). Endocrine. 2016;52:441-50. https://doi.org/10. 1007/s12020-015-0796-2.

61. Qureshi AI, Hanel RA, Kirmani JF, Yahia AM, Hopkins LN. Cerebral blood flow changes associated with intracerebral hemorrhage. Neurosurg Clin N Am. 2002;13:355-70. https://doi.org/10.1016/ s1042-3680(02)00012-8.

62. Tobieson L, Rossitti S, Zsigmond P, Hillman J, Marklund N. Persistent metabolic disturbance in the perihemorrhagic zone despite a normalized cerebral blood flow following surgery for intracerebral hemorrhage. Neurosurgery. 2019;84:1269-79. https://doi.org/10.1093/neuros/nyy179.

63. Gehlbach BK, Chapotot F, Leproult R, et al. Temporal disorganization of circadian rhythmicity and sleep-wake regulation in mechanically ventilated patients receiving continuous intravenous sedation. Sleep. 2012;35:1105-14. https://doi.org/10. 5665/sleep. 1998.

64. Gubin DG, Weinert D, Bolotnova TV. Age-dependent changes of the temporal order-causes and treatment. Curr Aging Sci. 2016;9:14-25. https:// doi.org/10.2174/1874609809666151130215824. 